\title{
Babel tropical
}

\section{Celeste Olalquiaga}

Celeste Olalquiaga es PhD en Estudios Culturales, Columbia University.

Sus libros Megalopolis: Contemporary Cultural Sensibilities (University

of Minessotta Press, 1992) y The Artificial Kingdom: a Treasury of

the Kitsch Experience (Pantheon Books, 1998) se han traducido a

varios idiomas y convertido en clásicos sobre la modernidad. Sus

temas incluyen el kitsch, las ruinas de la modernidad y la relación

entre naturaleza y tecnología. Ha recibido las becas Guggenheim

y Rockefeller. Radicada desde los años 80 en Nueva York, vivió

muchos años en París, donde realizó una investigación para un

libro sobre la petrificación, aún en progreso. Correo electrónico:

\section{Traducción de Juan Pizzani}

Juan Pizzani es estudiante del Doctorado en Antropología de la

Universidad de Los Andes, Mérida, Venezuela. Editor y compilador

de Perlongher, Néstor. Antología diacrónica (Caracas: El perro

y la rana, 2014). Autor de " $\mathrm{d}$ Esquizofrenia o Chamanismo? El

caso de un diagnóstico prematuro y reduccionista", Boletín

antropológico 83 (2012) y la novela Visita guiada (Caracas: El perro

y la rana, 2007). Correo electrónico: juanpizzani@gmail.com

\footnotetext{
Ensayo

Documento accesible en línea desde la siguiente dirección: http://revistas.javeriana.edu.co Publicado originalmente en http://prodavinci.com/2015/01/13/vivir/babel-

tropical-conozca-la-historia-de-el-helicoide-por-celeste-olalquiaga/

doi: 10.11144/Javeriana.cl20-39.batr
}

\section{Cómo citar este ensayo:}

Olalquiaga, Celeste. "Babel tropical". Cuadernos de Literatura 20.39

(2016): 398-406. http://dx.doi.org/10.11144/Javeriana.cl20-39.batr 
LA Torre DE Babel existe, no allá en Babilonia, sino aquí en América del Sur, en un país de infinitas plataformas petrolíferas y un record mundial de siete ganadoras del Miss Universo, felices clientas de la cirugía plástica. Venezuela, o la Pequeña Venecia, como llamaron los conquistadores a esta tierra donde los palafitos de los aborígenes, alzados sobre estacas de madera, les recordara a la famosa ciudad italiana rodeada por una laguna. La etimología arquitectónica de Venezuela pareciera haber anticipado su exuberante urbanidad, cuyo dinamismo es notable incluso en un continente donde la arquitectura excepcional no escasea.

Crucero encallado, platillo volador caído o ruina futurista, El Helicoide de Roca Tarpeya yace entre las barriadas de San Agustín, en la zona centro-sur de Caracas, produciendo una visión distinta según el ángulo desde donde se le vea. Asimismo, esta construcción cambia de acuerdo al sinfín de historias que la rodean, todas tan retorcidas como su magnífica estructura en doble espiral. Ambicioso proyecto prematuramente suspendido, El Helicoide fue fiel a su inspiración babilónica, si bien en su caso la construcción no se detuvo por interferencia divina, sino por mundanas cuestiones de la política. Al igual que su famoso antecesor, la construcción de este edificio, erigido en 1960 como centrocomercial automovilístico único en su modalidad, pues las personas hubiesen podido conducir sus carros a lo largo de sus curvas, estacionándose frente al comercio de su elección - fue detenida poco antes de concluir. El edificio fue entonces abandonado a su suerte, la cual incluyó deterioro y olvido, múltiples proyectos gubernamentales fallidos, ocupaciones por invasores y actividades de inteligencia policial. Escenario de episodios de drogas, prostitución y tortura, El Helicoide es una fuente de incontables leyendas, cada una más fascinante $-o$ aterradora- que la anterior.

En la década de los años 5o, la combinación de treinta años de ingresos petroleros y de un dictador - el General Marcos Pérez Jimenez, quien se dedicó a modernizar Caracas- hizo de Venezuela un paraíso para arquitectos provenientes del extranjero. Algunos, como Graziano Gasparini o Federico Beckhoff, adoptaron la ciudad capital como residencia permanente. Otros, incluyendo a Gio Ponti y Oscar Niemeyer, visitaron brevemente la ciudad atraídos por su orientación modernista. El primero contribuyó la famosa "Villa Planchart", la cual se mantiene intacta como ícono de los años 50 hasta el presente; el segundo propuso un enorme triangulo invertido como Museo de Arte Moderno para la ciudad, proyecto que nunca se ejecutó. Unos pocos colaboraron con colegas locales en el diseño de edificios únicos. Tal fue el caso de Marcel Breuer y Herbert Berckhard, quienes se asociaron con Ernesto Fuenmayor y Manuel Sayago en "El Recreo", un complejo comercial que nunca se llevó a cabo; fue el caso también de 
Dirk Bornhorst y Pedro Neuberger, dos jóvenes arquitectos venezolanos nacidos en Alemania, quienes fueron contratados para ayudar a construir la Caracas moderna por Jorge "Yoyo" Romero Gutierrez. "Hay tanto por hacer", decía Romero Gutiérrez, "todo es posible".

Así, se pusieron a la tarea junto a arquitectos de la talla de Carlos Villanueva, cuya Universidad Central de Venezuela - la cual ostenta un campus modernista de fluidas líneas y obras de arte de Léger, Arp, Vasarely y Calder, entre otros-fue declarada Patrimonio Cultural de la Humanidad por la UNESCO en el año 2000; o del osado Fruto Vivas, cuya espléndida concha acústica, la cual recubre el Club Táchira, es una importante muestra de arquitectura orgánica; o de Tomás José Sanabria, quien diseñara un hotel cilíndrico sobre el Ávila, El Humboldt, cuyo nombre conmemora al explorador alemán que presenció una lluvia de meteoritos en Venezuela durante su visita de 1799.

En 1955 Arquitectura y Urbanismo, la firma de Romero Gutiérrez, consiguió un importante contrato. El dueño de La Roca Tarpeya, un cerro de 30.472 metros cuadrados, quería construir una serie de pequeños edificios residenciales accesibles a través de una calle empinada. Romero Gutiérrez y sus socios concibieron un plan alternativo, cambiando la idea original de un proyecto residencial por otra, mucho más lucrativa, de uno comercial. Este constaría de una calle ascendiendo en espiral sobre la superficie abovedada del terreno, la cual serviría así como plataforma para los carriles superiores, forma económica y eficiente de aprovechar el espacio disponible. La vía se convertiría eventualmente en una ruta de aproximadamente 4 kilómetros, con niveles ascendentes y descendentes constituidos por dos espirales enroscadas, algo semejante a la doble hélice del código genético. Habría mil puestos de estacionamiento, dos por cada comercio de este complejo, alineados por el camino.

"El Helicoide: Centro Comercial y Exposición de Industrias" fue diseñado como un moderno centro comercial que albergararía enormes galerías para exhibir los adelantos de las florecientes industrias nacionales (petróleo, gas, hierro, aluminio y agricultura). Hubiera incluido asimismo una sala de exposiciones automovilísticas, un gimnasio y una piscina, restaurantes, guarderías, discotecas, un cine gigante, un hotel de primera con oficinas para todas las principales líneas aéreas, un helipuerto para transportar pasajeros desde y hasta el aeropuerto, y un sistema completo de acceso interno con ascensores diagonales y escaleras mecánicas. En su cima, bajo un domo diseñado por Buckminster Fuller, los visitantes podrían comprar souvenirs. El paisajismo iba a estar a cargo de Roberto Burle Marx. El Helicoide era arquitectura de punta, aún para los estándares de los Estados Unidos. 
"La construcción...", al decir de Bornhorst, el único de sus arquitectos que aún hoy vive, en su libro El Helicoide, "...fue concebida como una escultura urbana, una pièce de résistance arquitectónica, suavemente adaptada al ritmo de los cerros adyacentes, formando en sí misma otro relieve dentro de la topografía urbana..." en el valle de Caracas, cuyos cerros hacían soñar a los arquitectos con una Acrópolis tropical. El presupuesto para este desarrollo de 40.506 metros cuadrados de concreto armado fue calculado en diez millones de dólares. Al momento de ser abandonado, el monto había ascendido a veinticuatro millones.

La maqueta fue inaugurada en la oficina central de los arquitectos, el Centro Profesional del Este, en septiembre de 1955, con la presencia de Pérez Jímenez, alianza cuestionable cuyo alcance aún está por determinarse, pero la cual eventualmente le costaría la vida al proyecto. Poco después comenzó el colosal esfuerzo para alzar la torre enroscada, con un plan tan extremo como su forma: La Roca Tarpeya fue esculpida, centímetro a centímetro, para ajustarle El Helicoide como un guante. Esta estrategia limitó dramáticamente al edificio, pues quedó literalmente emparedado entre el cerro y su vialidad en espiral, contando con una profundidad máxima de 7 a 15 metros.

El Helicoide fue un hit instantáneo: su forma y escala atrajo la atención de los arquitectos de todo el mundo. Fotos de su maqueta aparecieron en la portada de periódicos del extranjero y ocuparon un lugar prominente en la exposición Roads del MoMA en 1961 (se prevé la aparición de El Helicoide en la retrospectiva sobre arquitectura latinoamericana de dicho museo para el 2015). En Venezuela una campaña publicitaria de preventa de los diferentes locales comerciales que el edificio albergaría (forma innovadora de recaudación de fondos para la época) produjo vasos, calcomanías y llaveros. Con la esperanza de que El Helicoide sería un catalizador del desarrollo urbano al sur de Caracas, se planificó un boulevard que conectaría al edificio con el Jardín Botánico, adjunto a la recién inaugurada Universidad Central de Venezuela. El poeta chileno Pablo Neruda escribió que El Helicoide era "uno de las creaciones más exquisitas que jamás nacieran de la mente de un arquitecto". Salvador Dalí se ofreció a decorarlo.

Entonces ocurrió lo impensable: el proyecto comenzó a paralizarse en un lento y gradual congelamiento que tomó a todo el mundo por sorpresa y del cual El Helicoide nunca se recuperó. En enero de 1958 Pérez Jiménez fue destituido. Al contrario de lo que se cree, El Helicoide aún no estaba en construcción, pues sólo se había tallado la Roca Tarpeya entre 1955 y 1957. La construcción como tal comenzó a fines de octubre de 1958, durante el gobierno militar provisional de Wolfgang Larrazábal, el cual efectuaría una transición a la democracia y permitió al edificio seguir adelante con tal de que sus empresarios contrataran a una serie 
de trabajadores desempleados como parte de un plan nacional de emergencia. Esto se hizo y El Helicoide avanzó a pasos agigantados, con 1.500 trabajadores alternándose en tres turnos consecutivos las veinticuatro horas del día durante el siguiente año y medio.

Fue la democracia la que propinó a El Helicoide el golpe de gracia. Aún no está claro cómo esto ocurrió. Algunos culpan al recién instaurado gobierno de Rómulo Betancourt, quien, poco dispuesto a continuar y legitimar la masiva renovación de Caracas llevada a cabo durante la dictadura, puso condiciones a una línea de crédito que le había sido otorgada previamente a El Helicoide. La compañía, Helicoide C.A., se detuvo, involucrándose en una larga disputa legal que terminaría en 1976 cuando el edificio vacío fue declarado propiedad del Estado. Otros, incluyendo a Pedro Neuberger, el tercero de sus arquitectos, afirmaron que luego de la destitución de Pérez Jiménez los principales accionistas de El Helicoide (incluyendo a la compañía IVECA, propiedad de Roberto Capriles) se fueron del país, dejando al edificio en una deriva financiera. En cualquier caso, los contratistas no recibieron su pago, y los comerciantes que habían comprado locales demandaron a la constructora, la cual cayó en bancarrota. Fin de la historia del Centro Comercial El Helicoide.

Durante los veinte años siguientes, esta construcción venezolana que logró obtener titulares a nivel mundial quedó sumida en un silencio casi absoluto. Sus arquitectos, desesperados por el fracaso de esta fantástica aventura, se dedicaron a otros proyectos. Caracas, fiel a su temperamento moderno que mira siempre hacia adelante y nunca hacia atrás, continuó su camino, olvidando a esa magnífica espiral que había buscado llegar al cielo del consumo. A decir verdad, los distintos gobiernos nacionales y locales posteriores intentaron salvar al gigante congelado. Una tras otra, cada administración propuso diferentes planes comerciales, culturales o combinaciones de ambos, llegando a proponer veintisiete proyectos en total: centro automovilístico, centro de artes escénicas, museo de arte, centro de turismo, cementerio moderno, estación de radio y televisión, multi-cine, biblioteca nacional, museo de antropología y centro ambiental son algunos de los más resaltantes.

De entre estas propuestas solo dos llegaron a ser comenzadas, otorgando algo de vida a los pasillos vacíos del edificio. Eso es, si no contamos las invasiones masivas que tuvieron lugar entre 1979 y 1982. En 1979, tras la reubicación oficial en El Helicoide de quinientos damnificados por los deslizamientos de tierras, pequeños grupos comenzaron a instalarse gradualmente en el edificio. Para 1982 la estructura inacabada albergaba doce mil invasores, todos viviendo sin servicios básicos en un área deprimida de la ciudad. El edificio se volvió una zona roja 
de tráfico de drogas y prostitución, con altos índices de criminalidad entre sus residentes.

Esta situación fue literalmente limpiada con fuerza hidráulica en 1982 para abrirle paso al Museo de Antropología. Con este proyecto se logró finalmente colocar sobre el edificio el domo de Buckminster Fuller, el cual había estado almacenado en un depósito por más de treinta años. Aun así, este plan no prosperó, a pesar de haber contado con la colaboración de Romero Gutiérrez, el arquitecto principal de El Helicoide, quien se negó a poner pie en el edificio pero brindó su asesoría a distancia. Por su parte, los ascensores austríacos Wertheim de alta tecnología, que habían sido construidos especialmente para este edificio, no corrieron con la misma suerte del domo. Con capacidad de carga para noventa y seis personas y diseñados para deslizarse diagonalmente sobre una inclinación de treinta grados a una velocidad de 2 metros por segundo, languidecieron en La Guaira, adonde habían llegado con gran fanfarria dos décadas antes. Para 1982, muy poca gente sabía siquiera qué eran aquellas enormes máquinas cuyas piezas eran dignas de ser exhibidas en un museo.

Poco después de que los planes del Museo de Antropología fueron abandonados apareció otro tipo de ocupante. En 1984 los servicios de inteligencia de la policía venezolana (antes DISIP, ahora SEBIN) comenzaron poco a poco a ubicar sus oficinas en El Helicoide, un panopticon perfecto con vista panorámica de Caracas en 360 grados. Una nueva oscuridad se cernió sobre el edificio, esta vez al ser transformado en un centro de reclusión. Se instaló equipo de vigilancia de alta tecnología y los oficiales se deleitaban con la posibilidad de conducir sus vehículos hasta la puerta de sus oficinas al estilo James Bond. Desde entonces El Helicoide alberga presos políticos, tortura y equipos SWAT que interceptan a cualquiera que ose fotografiar el edificio desde las autopistas circundantes.

Algunos creen que el lugar está maldito. El cerro, después de todo, recibe su nombre de la Roca Tarpeya de Roma, desde donde la hija de Tarpeyo, general de esa ciudad, fuera lanzada hacia su muerte por haber traicionado a Roma con los sabinos. En 1992, Julio Coll y Jorge Castillo, arquitectos de uno de los proyectos más progresistas elaborados para El Helicoide - El Centro Ambiental de Venezuela, diseñado para el Ministerio del Ambiente, respuesta admirablemente temprana en la región a un problema global- intentaron dispersar la energía negativa que parecía bloquear el desarrollo del edificio. Convencido de que parte del problema era el supuesto yacimiento de un cementerio aborigen en La Roca Tarpeya, el equipo tomó varias medidas para alinear las energías del lugar e incluso llevó a cabo una meditación silenciosa bajo el domo de Fuller. El proyecto logró ser completado en 1993: una magnífica sede que contaba con una biblioteca 
con nichos de mármol en el nivel superior del edificio. En vano, ya que el Centro Ambiental nunca se inauguró y a los pocos meses un nuevo gobierno se apropió de la despampanante sede para los altos mandos de la DISIP. La Roca Tarpeya había asestado otro golpe mortal.

Una década después, la DISIP comenzó a ser acompañada por escuelas de entrenamiento policial y militar, a saber, por la Universidad Nacional Experimental de la Seguridad (UNES) y la Universidad Nacional Experimental de las Fuerzas Armadas (UNEFA). Orgullosa de El Helicoide, la DISIP incluyó imágenes del edificio en la edición filatélica que conmemoraba su aniversario en el 2007. La institución policial fue reprendida pocos años más tarde, en junio de 2012, por la Corte Inter-americana de Derechos Humanos, la cual determinó que como centro de detención El Helicoide violaba convenciones internacionales de higiene para las prisiones. Un serio brote bacteriológico condujo finalmente a la transferencia de los presos a otras instalaciones, pero todavía hoy se realizan detenciones a cortos plazos en su sede. La ironía es asombrosa: un lugar que iba a ser la autopista al paraíso de los consumidores se convirtió en un tobogán al infierno, como si la espiral, en lugar de ascender, hubiera descendido. Giro particular del referente sacro de El Helicoide, el zigurat, pues el zigurat no solo nos conecta con el cielo, sino también con la tierra bajo nuestros pies. El Helicoide, un zigurat tropical a la deriva.

Hay rumores de que El Helicoide tiene túneles subterráneos que llegan a diferentes partes de la ciudad. Cual una hélice risomática cuyas volutas esparcen desperdicio y desilusión, las barriadas alrededor del edificio se han multiplicado, así como el cuerpo de seguridad instalado en sus entrañas. Los barrios envuelven tan de cerca al edificio que se fusionan topográficamente con sus curvas, mientras que este sirve de plataforma para operaciones policiales. El Helicoide, una extraña y surreal plataforma, tan inusitada, impredecible y singular como la fisionomía siempre cambiante de Caracas.

Para la mayoría de los caraqueños, El Helicoide es simplemente parte del paisaje, uno de muchos edificios inacabados o abandonados de los años 50 y 6o, cuando Caracas atravesó su boom moderno y se expandió en todos los sentidos. Fue un tiempo utópico que algunos recuerdan con profunda nostalgia, ya sea por el régimen dictatorial que dio a la ciudad su infraestructura moderna, ya por la democracia floreciente que advino inmediatamente después de décadas de dictaduras casi consecutivas, cada una estampando su carácter distintivo al fértil valle que otrora albergara haciendas de café y tabaco.

En las cuatro décadas que siguieron al descubrimiento del petróleo en 1918, Caracas pasó de un pueblo tranquilo y semi-rural de 140.00o habitantes a 
una capital efervescente de América con una población de más de 1.2 millones de personas, repleta de autopistas, rascacielos y escuelas para las familias de las compañías petroleras extranjeras (Shell, Mobil, Exxon) que se afanaban en bombear petróleo venezolano. Al igual que ese petróleo, la recién nacida democracia surgió llena de proyectos, ávida de asir una modernidad para la que Venezuela parecía finalmente madura, lista para ponerse al día con un mundo que por mucho tiempo había admirado. Sin embargo, al igual que muchas otras naciones, esta democracia se construyó a costa de una vasta mayoría a la que rara vez se visibilizaba y mucho menos reconocía. La "fiesta fabulosa", como los venezolanos llamaron al período de las décadas de los 40 a los 7o, llegó a su fin en 1999 con el auge de la Revolución Bolivariana liderizada por Hugo Chávez. Pero la fiesta había terminado mucho antes. El Helicoide es testimonio de esos extremos que han llevado a Venezuela del entusiasmo a la desesperación una y otra vez.

La modernidad es una condición truculenta, especialmente en un país como Venezuela, con un boom petrolero que irrumpió en medio de una economía semi-feudal. Ponerse al corriente de las tendencias mundiales no es igual a progresar o independizarse como nación y sin embargo, en Venezuela, ponerse al día significó convertirse, si no en igual, al menos en un jugador comparable a su complicado vecino del norte, los Estados Unidos. Se trató entonces de emular el modelo de América del Norte, entendido como modelo del futuro, de un progreso basado en los paradigmas de la inversión capital y la eficiencia mecánica. Ponerse al día significó, en forma típicamente venezolana, ganarle a los "gringos" en su propio juego: por ejemplo, construyendo un centro comercial que los dejara boquiabiertos.

Y así sucedió. En el catálogo para la exposición Roads de 1961 en el MoMA, Bernard Rudofsky y Arthur Drexler comentaban admirados que El Helicoide era "un emprendimiento osado realizado en Latinoamerica y no en los Estados Unidos, donde tanto las autopistas como los centros comerciales han contado entre nuestros esfuerzos más ambiciosos". Esto era tan cierto que Nelson Rockefeller intentó comprar El Helicoide, pero no pudo superar el complejo litigio legal que paralizó a la construcción. El Helicoide fue una hazaña de la imaginación y la tecnología en un contexto donde estas cosas son secundarias, donde la continuidad no existe y el mantenimiento es considerado una pérdida de tiempo. Un contexto en el cual las motivaciones son presa de políticas de apropiación que subordinan al país a sus líderes en una perversa filiación.

El Helicoide representa lo contrario de aquello para lo cual fue construido. En lugar de un dinámico centro de intercambio comercial que pudo haber revitalizado la zona y sus alrededores, el edificio creció melancólicamente hacia 
adentro, condenado, como un pensamiento obsesivo, a repetirse una y otra vez. En lugar de resultar expansivo, se convirtió en una fortaleza amenazadora de "la ley y el orden" en un país que los ignora sistemáticamente. La torre que pudo haberse vuelto un símbolo del empuje progresista de la modernidad se convirtió en un emblema de sus fracasos, del precio que se paga por desear cambiar todo a cualquier costo, por imponer una visión unilateral, por soñar por los demás lo que quizá ellos no deseen soñar para nada. Muchos piensan que, en su condición de ruina, El Helicoide ofrece el retrato distópico más apropiado de Caracas.

Durante los últimos treinta años, El Helicoide ha actuado como un sol negro, irradiando control estatal, detenciones y violencia. Para algunos, este destino es mejor que el abandono total, pero está muy lejos de sus grandiosas aspiraciones iniciales. Y más lejos aún de la sagrada geometría que subyace las pirámides y los templos, la danza espiral al origen de toda vida presente en estas estructuras. Tallado literalmente en la piedra, El Helicoide durará cientos de años, al igual que aquellas construcciones ancestrales, sobreviviendo incluso explosiones nucleares. Permanecerá como ícono de un futuro que nunca llegó al presente. 